\title{
Maximizing Usage of Power Supply through Electrical Power Distribution Company or Generator By means of Power Inverter System
}

\author{
Babalola I.T1 ${ }^{1}$, Yekini N.A2*, Adebari F.A ${ }^{3}$, Ajayi Temitope ${ }^{4}$ \\ ${ }^{1}$ Department of Electrical and Electronic Engineering, Yaba College of Technology, Yaba, Lagos State, Nigeria \\ 2,3Department of Computer Engineering, Yaba College of Technology, Yaba, Lagos State, Nigeria \\ ${ }^{4}$ Department of Industrial Maintenance Engineering, Yaba College of Technology, Yaba, Lagos State, Nigeria
}

\section{${ }^{*}$ Corresponding Author}

Yekini N.A

\section{Article History}

Received: 06.07.2019

Accepted: 22.07.2019

Published: 30.07 .2019

\begin{abstract}
There is no doubt that unstable and erratic supply of electricity to support human endeavor in Nigeria has been a topic of dialogues over decades. Also distribution company only distribute energy at their own discretion without considering whether it is useful to end users or not. Several alternative salutations have been proposed to solve the problems arise from discretional supply of power to end users. This research work devised the design and implementation of the 1.5KVA Power Inverter to store the supply from the distribution company. This work designs and delivers electrical power supply that takes it source from a battery converting the zero variation signal of the generated $D C$ voltage to a standard $240 \mathrm{v} \mathrm{AC}$ sinusoidal voltage. The output of this research work will consists of an oscillator which inverts the DC signal to AC, a transformer that amplifies the voltage, MOSFETs which amplifies the current, relay for automatic switching and a charging back system to recharge the battery whenever there is an alternative mains (PHCN or generator).
\end{abstract}

Keywords: inverter, distribution company, MOSFETs, $A C$ sinusoidal voltage, $D C$ voltage

\section{INTRODUCTION}

The important of electricity to human endeavor and economic growth of a country cannot be underscored. The artisans, government agencies, corporate companies, hospital, schools depends on electricity for survival and sustainability growth. The problem of electricity supply in Nigeria has gone beyond what is supply but mainly on utilization of the supply. This statement of mine was corroborated by the minister of works, power, and housing at the convocation lecture of Yaba College of Technology where he challenges the academic community on research for storing of power supply [1].

There are various approach to power storages which includes: Tesla Powerwall/Powerpack: Redox flow battery; Flywheel energy storage; Compressed air energy storage; Thermal energy storage. Series of battery units can be network to store up to $129 \mathrm{MW}$ of power that can be supplied on request to the end users. non-technical.

[2] Electricity supply chain includes: generation, transmission and distribution. Losses are classified into either technical or

This research work is focus on design of inverter with a relay for automatic switching and a charging back system to recharge the network of battery whenever there is supply from power Distribution Company or generator. This research work aim at making power available on demands or when needed. The output of this research work can be modified by the power distribution company in Nigeria for storage of power supply to them and distribute or transmit it on demands to the end users when needed, this will go long way to prevent Non-technical losses in power distribution.

Copyright @ 2019: This is an open-access article distributed under the terms of the Creative Commons Attribution license which permits unrestricted use, distribution, and reproduction in any medium for non commercial use (NonCommercial, or CC-BY-NC) provided the original author and source are credited. 


\section{LITERATURE REVIEW \\ Power Losses}

"Electricity supply chain includes: generation, transmission and distribution. Generation involves the production of electricity using appropriate technology from a primary source which could be natural gas, coal, nuclear material or renewable sources such as hydro and solar energy. Electricity is generated at low voltage and high current and channeled through a network of transformers and conductors over long distances to various locations where it can be used. This is known as transmission. At the various locations, the electricity is then broken down into smaller sizes and distributed to various households, businesses and factories for consumption. This is the distribution phase" "The amount of electricity generated that can be delivered by the transmission and distribution network is known as the efficiency of the system. The more efficient the system, the less of power is lost and the more of it is available to be transmitted to the consumer. Power generated, but not delivered for consumption or not paid for by consumers are known as losses, losses are divided into two categories; technical i.e Technical losses occur as a result of power dissipation in components of the electricity system such as transmission and distribution lines and transformers, and non-technical losses, commercial and collection losses. Commercial losses refer to energy received by the electric utility but not billed for. It comprises losses due to power dissipation in distribution lines, meter tampering, illegal connections and free users (customers connected to distribution lines but not known by the utility). Collection losses refer to energy billed for but not collected. It comprises billing errors, unpaid bills as well as collusion between utility staff and customers to alter bills. Most of the components that constitute non-technical losses can be categorized as electricity theft" [3]

\section{Electricity theft}

"Electricity theft is the careful and determined criminal deed of electric power stealing, it is a deliberate consumer activities to cut down or reduce the total amount of tariff payable on electricity consumed, resulting in total or partial loss of revenue due to the utility provider" [4]. Electricity theft is one of the major problem facing electrical distribution company in Nigeria. Several users of the power supply from Distribution Company bypass meter or connive with workers of the various distribution company to perpetuate the crime. The activity of consumers in connivance with some DisCo officials has resulted in huge electricity theft, and is affecting the efficiency of DisCos in meeting the user demands due to loss from distribution lapses" [5]. Wealthy and literate Nigerian engage more in the act of power theft compare to poor masses and illiterate, these wealth and illiterate people engaged in the illegal act by either tampering with their meters or connecting illegally to service points [6].

\section{Energy Storage Technologies}

"Energy storage systems provide a wide array of technological approaches to managing our power supply in order to create a more resilient energy infrastructure and bring cost savings to utilities and consumers, there are six main categories of energy storage technologies: Solid State, Flow Batteries, Flywheels, Compressed Air Energy Storage, and Pumped Hydro-Power Energy [7].

\section{DESIGN AND IMPLEMENTATION}

Design specification was carried out follow by modelling. Overall System Configuration was given as follows:

\section{Overall System Configuration}

Input Supply (from Battery) .....

Mode of Power (Inverter)

Power Requirement

Efficiency

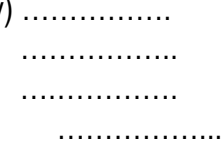

$\mathrm{DC}$

$D C$ to $A C$ Inversion

1500VA

$80 \%$

\section{Battery Specification}

Rated Voltage

Storage Capacity

Type $\quad$.........

\section{$12 \mathrm{~V}$}

Sealed lead Acid Rechargeable Battery

\section{Voltage Regulation}

Cycle use ......... 13.2V - 13.5V

Standby use ......... $\quad 12.75 \mathrm{~V}-12.9 \mathrm{~V}$

\section{Maximum Charging Current}

$$
\begin{gathered}
\text { The maximum power output }\left(I_{C}\right)=\frac{\text { maximum power }}{\text { open circuit voltage }} \\
=\frac{60}{36.3}=1.7 \mathrm{Amps}
\end{gathered}
$$

\section{Load Specification}

An Alternating Current 240V operating load

Load Wattage. 1.5- 1000 Watts $\pm 5 \%$ 


\section{Safety Specification}

Maximum system open circuit

Series fuse

$5 \mathrm{~A}$

Electric and Fire Safety

\section{Class C Fire}

\section{Charging Time}

A number of key factors contribute to the charging capacity of the project and the project and the overall time taken to charge the battery. These factors are hereby listed below:

1. The storage capacity of the battery.

2. The type of battery (Lead Acid or Deep Cell).

3. The amount of electrical energy remnant in the battery after it is used.

The charging time (measured in hours) is determined by the ratio of the battery capacity (Amps- hour) to the local power supply (PHCN) charging current (Amps).

\section{Inverter Specification}

$\begin{array}{ll}\text { Rated Power } & 1200 \mathrm{~W}, 1500 \mathrm{VA} \\ \text { Input Voltage } & 12 \mathrm{~V} \mathrm{DC} \\ \text { Output Voltage } & 240 \mathrm{~V} \mathrm{AC} \\ \text { Output Frequenc } & 50 \mathrm{~Hz} \\ \text { Series Fuse Rating } & \frac{\text { Power }}{\text { Voltage }}=\frac{1200}{240}=5 \mathrm{Amps}\end{array}$

This system is first modelled as shown in figure 1 below. The inverter will receive the AC input from any source and thereafter charged the networked battery in the battery bank. The battery bank store the power not currently needed. The stored power can then be used on demands.

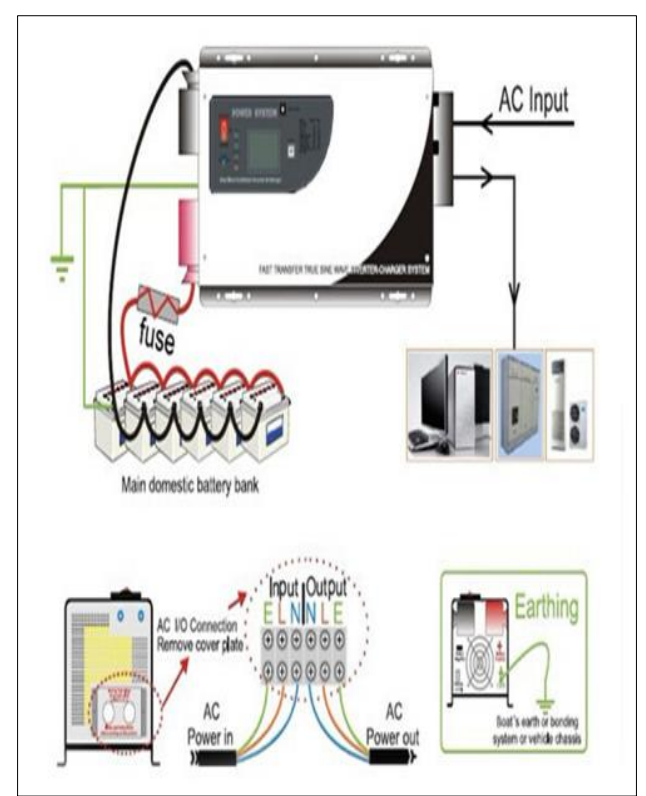

Fig-1: Prototype of proposed system

The circuit design for the inverter was carefully done using printed circuit board (PCB). Material used include: Glossy paper; Toner printer; Electric pressing iron; Copper board; Etching solution (ferric chloride solution); Software (ultism). Ultim software was used to the PCB layout and the circuit was simulated on the same software to verify the connection of the components. After simulation and no error then the layout was printed out on a glossy paper using a laser printer and the following method was adopted accordingly:

- The print out was placed on the glossy paper on the copper board and the copper board was cut to the circuit size.

- We used blade to scrape off the copper side of the board and place the surface of the printed PCB layout circuit on the scrapped copper surface of the copper board and use an adhesive tape to lock down the paper on the board.

- We used an electric iron turned to its maximum heat (cotton position) as the iron warms up, the paper was placed on the copper board and the electric iron was placed on the paper with much pressure applied to enable the PCB layout circuit display on the copper board boldly. 
- After ironing the PCB layout circuit display on the copper board still stapled was soaked in water for few minutes for it to soften the paper. Few minutes later the paper was peeled off. The copper board was placed into the solution (ferric chloride solution) for few minutes.

- After few minutes the copper board was removed from the solution (ferric chloride solution) with a black stained, the black stain was washed off from the copper board and dry it. The final PCB layout is as shown in figure 2.

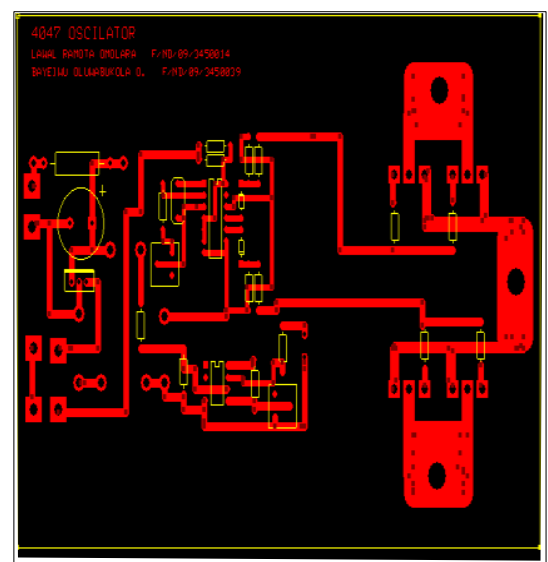

Fig-2: PCB layout

The final PCB layout was implemented as necessary holes on the board were drilled and components soldered on the board as shown in figure 3,4 , and 5 respectively. Figure 4 shows the placement of the components on the PCB board but the components are placed on the opposite side of the printed side of the board.

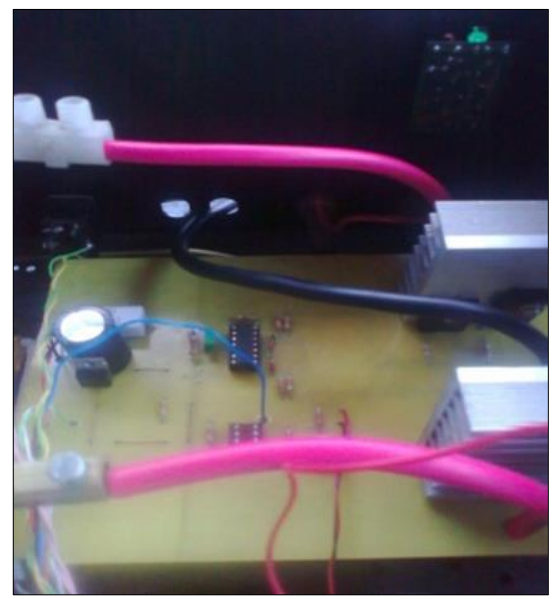

Fig-3: Stage 1 of fixing and soldering components on PCB

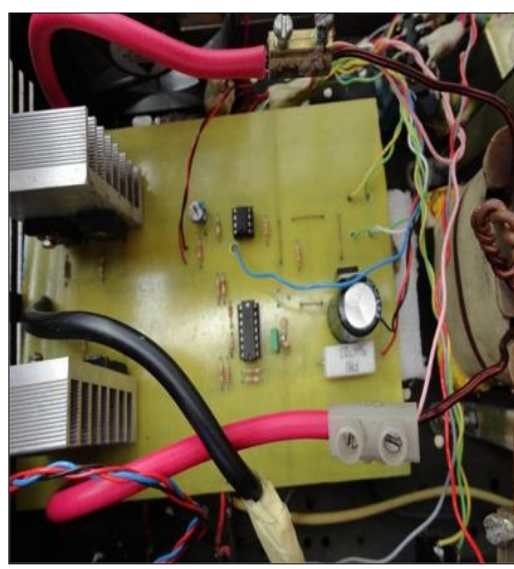

Fig-4: Stage 2 of fixing and soldering components on PCB 


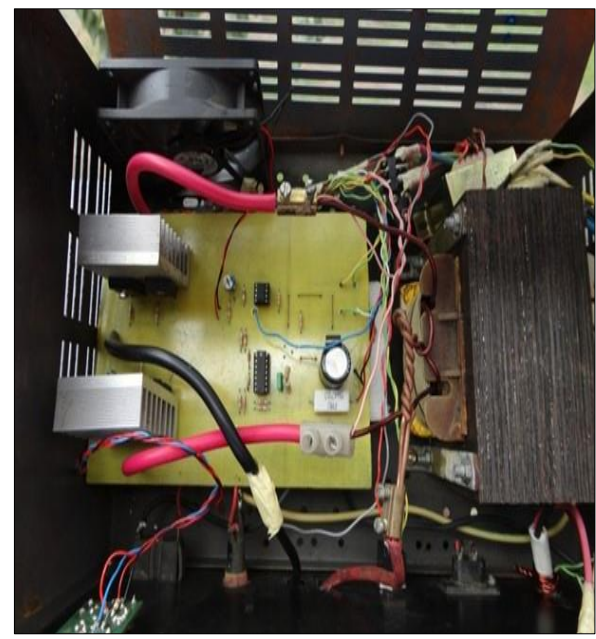

Fig-5: Stage 3 of fixing and soldering components on PCB

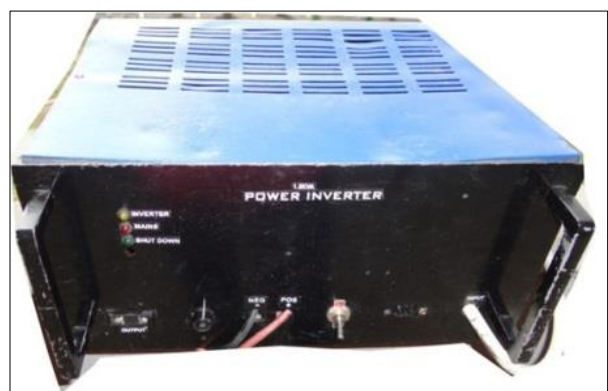

Fig-6: Fully packaged and ready to use Inverter

\section{Testing and Discussion}

Modular testing was adopted in every stages of design. The final product in figure 6 was then tested. The AC supply was connected to the power inverter and polarity test, continuity Test, and insulation resistance test was carried out.

\section{CONCLUSION}

The design and construction of the power inverter was designed and constructed to desired specifications. The output can be used in many places where efficient and continuous supply of electricity is needed such as homes, industries, hospitals etc. This research work output is not only meant to enhance efficiency in power supply. It will also go a long way to store energy for distribution on demands.

\section{REFERENCES}

1. Raji, F. (2018). Sustainability of Technological Advancement-Key to Industrial Growth. YabaTech Convocation lecture

2. Power electronic, (2017). 6 Promising Energy Storage Options to Tie into the Grid available at https://www.powerelectronics.com/alternative-energy/6-promising-energy-storage-options-tie-grid. Retrieved on Janauary 7 , 2019.

3. Cpparesearch. (2018). Mitigating Electricity Theft In Nigeria. http://cpparesearch.org/nu-en-pl/mitigating-electricity-theft-nigeria/

4. Abuja Electricity Distribution Company (n.d). Electricity Theft - Abuja Electricity Distribution Company. available at http: www.abujaelectricity.com/wp-content/uploads/Circular-on-Electricity-Theft.pdf

5. Adetoba, B. T., Yekini, N. A., Lawal, O. N., Alakiri, H. O., \& Alakiri, H. O. Enhancing Billing and Minimization of Electricity Theft in the Electrical Po Electrical Power Distribution via ICT wer Distribution via ICT.

6. NERC. (2016). Nigeria: Wealthy, Not Poor Nigerians Stealing Electricity, NERC Claims. Available at Storage Association 2018. Energy Storage Technologies. http://energystorage.org/energy-storage/energy-storage-technologies. 